Revue interdisciplinaire sur la Grèce archaïque

$21 \mid 2018$

Varia

\title{
Ouvrages reçus en 2017
}

\section{(2) OpenEdition \\ 1 Journals}

Édition électronique

URL : https://journals.openedition.org/gaia/430

DOI : 10.4000/gaia.430

ISSN : 2275-4776

Éditeur

UGA Éditions/Université Grenoble Alpes

\section{Édition imprimée}

ISBN : 978-2-37747-057-0

ISSN : 1287-3349

\section{Référence électronique}

"Ouvrages reçus en 2017 », Gaia [En ligne], 21 | 2018, mis en ligne le 01 novembre 2018, consulté le 10 décembre 2021. URL : http://journals.openedition.org/gaia/430 ; DOI : https://doi.org/10.4000/ gaia. 430

Ce document a été généré automatiquement le 10 décembre 2021.

Gaia. Revue interdisciplinaire sur la Grèce archaïque 


\section{Ouvrages reçus en 2017}

\section{NOTE DE L'ÉDITEUR}

Cette liste concerne les ouvrages envoyés gracieusement au bureau du site homerica et de Gaia à la Maison des sciences de l'homme de Grenoble. Ils sont enregistrés sur le site Homerica dans la rubrique Livres. Nous remercions Marc Chanove et Florent Gruber pour le travail qu'ils ont fait pour le site, ainsi que les éditeurs et auteurs qui nous font ces envois. La liste est arrêtée au 30 janvier 2018.

AHRENSDORF Peter J., Homer on the Gods \& Human Virtue. Creating the Foundations of Classical Civilization, Oxford, Oxford University Press, 2014.

ALDEN Maureen, Para-Narratives in the Odyssey. Stories in the Frame, Oxford, Oxford University Press, 2017.

Anabases. Traditions et Réceptions de l'Antiquité, 24, 2016, Les sarcophages des époux; Vassilis Alexakis, lecteur de Plutarque; Les présocaratiques dans la Chine des années 20; Max Weber et l'Antiquité; Le site Pictor in Fabula.

Annali della Scuola Normale Superiore di Pisa, Classe di Lettere e Filosofia, serie 5, 2017, 9/1.

Annali della Scuola Normale Superiore di Pisa, Classe di Lettere e Filosofia, serie 5, 2017, 9/2, supplemento Rassegna archeologica.

Anzeiger für Altertumswissenschaft, 67 (1-2), janvier-avril 2015 et 67 (3-4), juilletoctobre 2015, Innsbruck, Universitätsverlag.

Athenaeum. Studi di Letteratura e Storia dell'Antichità dell'Università di Pavia, 105 (1-2), 2017. AUC Philologica, 2, 2017, Marciana in honorem Vaclav Marek, editors Ivan Prchllik and Ján Bakyta, Acta Universitatis Carolinae, Charles University in Prague.

BIRAUD Michèle \& BRIAND Michel (éd.), Roman grec et poésie. Dialogue des genres et nouveaux enjeux $d u$ poétique, Lyon, Maison de l'Orient et de la MéditerranéeJean Pouilloux, « CMO, 56 », 2017.

CASSIN Barbara (dir.), Philosopher en langues. Les intraduisibles en traduction, Paris, Éditions rue d'Ulm, coll. «Études de littérature ancienne, 23 », 2014.

CAZZATO Vanessa, OBBINK Dirk \& PRODI Enrico Emanuele (éd.), The Cup of Song. Studies on Poetry and the Sympsosion, Oxford, Oxford University Press, 2016. 
CURRIE Bruno, Homer's Allusive Art, Oxford, Oxford University Press, 2016.

Eikasmos. Quaderni bolognesi di filologia classica, 27, 2016 et 28, 2017, Bologne, Pàtron editore.

Eirene. Studia graeca et latina, 52 (1-2), 2016, Papyrologia IV Varia Classica, Prague, Institute for Classical Studies.

Fabrique de la déclamation antique (Controverses et suasoires), textes recueillis et présentés par Rémy Poignault et Catherine Schneider, Lyon, Maison de l'Orient et de la Méditerranée-Jean Pouilloux, « CMO, 55 », 2016.

FANTUZZI Marco \& TSAGALIS Christos (éd.), The Epic Cycle and Its Reception. A Companion, Cambridge, Cambridge University Press, 2015.

FINGLASS P.J. \& KELLY Adrian (éd.), Stesichorus in Context, Cambridge, Cambridge University Press, 2015.

Food \& History, 13 (1-3), 2015, dossier L'imaginaire de l'alimentation humaine en Grèce ancienne, Jocelyne Peigney et Brigitte Lion (éd.).

Gaia, 20, 2017, dossier Toucher le corps dans l'Antiquité, Jean-Christophe Courtil et Régis Courtray (éd.).

HELDMANN Konrad, Europa und der Stier oder der Brautraub des Zeus. Die Entführung Europas in den Darstellungen der Griechischen und römischen Antike, Göttingen, Vandenhœck \& Ruprecht, 2016.

HUNZINGER Christine, MÉROT Guillemette \& VASSILIADÈS Georgios (éd.), Tours et détours de la parole dans la littérature antique, Bordeaux, Ausonius, 2017.

Invigilata Lucernis. Rivista di scienze dell'antichità e del tardoantico, 38, 2016, Edipuglia.

Lucien de Samosate. Portrait du sophiste en amateur d'art, textes édités par Sandrine Dubel, postface de Jackie Pigeaud, Paris, Éditions rue d'Ulm, coll. «Études de littérature ancienne, $22 », 2014$.

Kernos, 30, 2017, Liège, Centre international de la religion grecque antique.

NOWICKI Joanna \& RADUT-GAGHI Luciana (dir.), Rêves d'Europe, Paris, Honoré Champion, coll. « Histoire culturelle de l'Europe, 14 », 2017.

PETRIDOU Georgia, Divine Epiphany in Greek Literature and Culture, Oxford, Oxford University Press, 2015.

Phoenix, 70 (3-4), 2016 et 71(1-2), 2017, Classical association of Canada / Société canadienne des études classiques.

PIRONTI Gabriella \& BONNET Corinne, Les dieux d'Homère. Polythéisme et poésie en Grèce ancienne, Liège, Presses universitaires de Liège, 2017, Kernos, supplément 31.

PORTER James I., The Sublime in Antiquity, Cambridge, Cambridge University Press, 2016. SAUZEAU Pierre \& SAUZEAU André, La bataille finale. Mythes et épopées des derniers temps dans les traditions indo-européennes, Paris, L'Harmattan, 2017.

SCAFOGLIO Giampiero, Ajax, un héros qui vient de loin, Amsterdam, Adolf M. Hakkert, 2017.

THOMAS Joël, Les mythes gréco-romains ou la force de l'imaginaire. Les récits de la construction de soi et du monde, Louvain-la-Neuve, Academia, coll. « Imaginaires », 2017. TREDÉ-BOULMER Monique, Kairos. L'À-propos et l'occasion. Le mot et la notion, d'Homère à la fin du IV siècle avant J.-C., Paris, Les Belles Lettres, 2015. 